of a plate, gave a track of an $\alpha$-ray of energy $10^{8}$ electron volts. The ion content of the air roughly follows the cosmic ray activity at great heights. Previous records only went up to $30,000 \mathrm{ft}$. In these experiments, the maximum was observed at $61,000 \mathrm{ft}$. of 81 times that at sea-level, and at the greatest height of $72,000 \mathrm{ft}$. this figure fell to 50 . There may be some connexion between this and the observed decrease in the strength of radio signals received on the ground from above a height of $60,000 \mathrm{ft}$. Other results quoted are that 20 per cent of the ozone content of the atmosphere lies below 72,000 ft., the composition of stratosphere air is insignificantly different from that at sea-level and above $60,000 \mathrm{ft}$. only moderate wind velocities ranging up to 42 miles per hour are met with. From the temperature-altitude chart given, it appears that the temperature ranged round about $-70^{\circ} \mathrm{F}$. from $35,000 \mathrm{ft}$. to the maximum heights from 9.40 a.m. to 2 p.m.

\section{The Impact of Science on Social Organisation}

THE twenty-eighth Moncure Conway Memorial lecture was delivered on May 20 by Prof. Lancelot Hogben, who dealt especially with the impact of scientific knowledge on contemporary social organisation. The democracies of Western civilisation, Prof. Hogben said, have reached a crisis with which a social personnel of government trained in a humanism without roots in scientific technology are not equipped to deal. Current political thought is permeated with a body of economic doctrine which includes within its scope no conspectus of emergent technological forces reshaping national policy and international relations. The result is a growing distrust of the powers of education and rational persuasion. In the long run, the stability of Western democracy must depend on whether we can devise an education adapted to the conditions of a society which makes increasing demands on technical knowledge. The necessary reorientation of cultural values and of research in social studies can only be brought about by enlisting to the task a new personnel with naturalistic training and the executive competence which laboratory experience calls forth. The primary business of social inquiry should be devising the social machinery to make available for human welfare the plenty which science offers. The lecture is published by Messrs. Watts and Co., 5 and 6 Johnson's Court, Fleet Street, London, E.C.4 (price 2s. net; by post, $2 s$. 2d.).

\section{Chemistry of Crystals}

THE thirty-fourth Bedson Lecture was delivered at Armstrong College, Newcastle-upon-Tyne, on May 8, by Dr. C. H. Desch, his subject being "The Chemical Properties of Crystals". Dr. Desch said that a solid metal is a crystalline mass of which the chemical, as well as physical properties are anisotropic; acid attack, for example, not being uniform, but producing geometrically shaped pits indicating the symmetry of the constituent crystals. This constitutes a part of the evidence for a secondary or mosaic structure in crystals. The boundaries between the individual crystals have different chemical properties from the mass. Their form corresponds with that of foam cells, being determined by surface tension, and in certain alloys they can be separated by the action of specific reagents. Certain brasses containing aluminium, for example, fall to pieces, the grains separating like sand, when placed for a few seconds in a solution of mercurous nitrate. In the stainless steels, such intercrystalline disruption is explained by the segregation of carbides, but in other instances no boundary constituent has been detected. The stability of iron, aluminium and stainless steel in air is explained by the presence of a surface film of oxygen or oxide. The greatly increased chemical activity of a metallic surface under high local pressures, as in abrasion, was also discussed. The effect known as 'corrosion fatigue' is caused by the combined action of alternating stresses and chemical attack, in which the properties of the film and of minute cracks both play a part. Dr. Desch concluded with an account of the transformations within solid solutions, including the work of Prof. W. L. Bragg on the changes from disorder to order in a lattice.

\section{Lectures to Secondary School Pupils}

WITH the object of bringing young people from secondary schools into contact with some aspects of progressive science and its applications, the British Science Guild arranged last year for two lectures by Mr. C. C. Paterson, director of the research laboratories of the General Electric Company, to pupils from secondary schools for girls in the London area. The lectures were delivered at the Institution of Electrical Engineers, and the subject was "The Electron Liberated: its Industrial Consequences". Sir Albert Howard, the honorary secretary of the Guild, has provided for the continuance of this successful enterprise under the title of the Gabrielle Howard Memorial Lecture; and on Tuesday and Wednesday last, May 26 and 27, Prof. W. L. Bragg delivered this lecture upon the subject of "Telegraphs and Telephones". The lecture on the first day was to boys from London Secondary Schools, and on the second to girls from London Secondary Schools. On both occasions, the lecture was given at the Royal Institution, by kind permission of the Managers. Through the courtesy of Messrs. G. Bell and Sons, the young people who attended the lectures were able to take away with them a pamphlet containing a reprint of the chapter on telegraphs and telephones from Prof. Bragg's book on "Electricity" just published by Messrs. Bell.

\section{Whirlpools and Vortices}

AT the Friday evening discourse at the Royal Institution on May 22, Prof. E. N. da C. Andradel discussed "Whirlpools and Vortices". The best example of what is ordinarily thought of as a vortex is the whirlpool that is formed where the water runs out of a bath or basin. There is a widespread belief that this always spins one way, clockwise or counter-clockwise, and that this is due to the rotation 